\title{
STUDY OF THE TOXIC ACTION OF CHEMICAL WEAPONS THROUGH THE USE OF SIMULANTS
}

\author{
V. Ivanov ${ }^{1 *}$, N. Bozakova ${ }^{2}$, V. Petrova-Tacheva ${ }^{3}$, M. Platikanova ${ }^{4}$, V. Slavova ${ }^{1}$ \\ ${ }^{1}$ Department of Neurology, Psychiatry and MDS, Faculty of Medicine, Trakia University, \\ Stara Zagora, Bulgaria \\ ${ }^{2}$ Department of General Animal Breeding, Animal Hygiene, Ethology and Animal Protection Section, \\ Faculty of Veterinary Medicine, Trakia University, Stara Zagora, Bulgaria \\ ${ }^{3}$ Department of Molecular Biology, Immunology and Medical Genetics, Faculty of Medicine \\ Trakia University, Armeyska 11, Stara Zagora, Bulgaria \\ ${ }^{4}$ Department of Hygiene, Infectious Diseases and Epidemiology, Faculty of Medicine, Trakia \\ University, 11 Armeyska Street, Stara Zagora
}

\begin{abstract}
Chemical weapons have been used repeatedly in the history of mankind in a number of wars and terrorist acts. They have caused major damage to human health and taken many lives. Instead of chemical weapons, various simulants - compounds with a similar action of these weapons, but without such high toxicity for human health - could be used for developing antidotes to specific chemicals, doing research on detecting them, developing sorbents for gas masks, military exercises, etc.

The purpose of this report is to examine the possibilities of using chemical weapons through their simulants which resemble their toxic effects.
\end{abstract}

Key words: chemical warfare agents, tabun, sarin, soman, sulfur mustard

\section{INTRODUCTION}

Chemical weapons have been repeatedly used in human history. They have damaged the health or killed many people. They pose a serious threat to the environment.

In many cases, instead of using real warfare agents, simulants can be used, especially in scientific research on the mechanisms of toxic action; in the process of developing antidotes; when experimenting on and studying their resorption through the skin; when developing means of protection, decontamination solutions and lotions; when studying the process of degradation of real warfare agents; when developing means and methods of detection; when carrying out military training, etc. Warfare agent simulants have very similar manifestation of a particular real warfare agent but, at the same time, pose lower risk to researchers, military staff and civilians. Their toxicity is lower and by rule, they are not that easily absorbed through the skin.

\footnotetext{
*Correspondence to: Veselin Ivanov, 11 Armeyska Str, 6000 Stara Zagora, Bulgaria, Phone: +35942664326, E-mail: veskoasenov@abv.bg
}

The team of authors has a rich experience in using simulants when researching the process of chemical warfare agents sorption in gas mask sorbents and in the eventual development of new sorbents.

The purpose of this paper is to present ways of using chemical warfare simulants, mimicking the toxic action of real warfare agents but much less dangerous for the people involved.

\section{Presentation}

During the 1930s Strader's group carried out experiments on the toxic action of tabun, sarin, and soman with the purpose of using these chemical compounds as herbicides and insecticides for agricultural protection (1). An accident occurred and caused them severe intoxication. That incident gave clear indication of their potential as chemical warfare agents. In the years to come, they have repeatedly been used killing many people. These chemical compounds irreversibly inhibit acetylcholine esterase, an enzyme which acts in the mechanism of neural impulse transfer to the synapses. A similar action mechanism is observed in the later developed V-gases and the so called "novichki" nerve agents. Zelinski 
IVANOV V., et al.

experienced quite the same case of intoxication when researching and experimenting with sulfur mustard (mustard gas) (2).

Warfare agent simulants can be used when studying the mechanisms of their toxic action, when researching the absorption of warfare agents through the skin, or when developing new antidotes.

A team of scientists have synthesized a nontoxic and harmless analogue of sarin, isopropyl p-nytrophenyl methylphosphonate (INMP) for safe simulation of acetylcholine esterase (AChE) inhibition when exposed to sarin. This substance stays stable for years and can be used in ordinary laboratories, without specific protection measures. This reagent is considered very useful since it allows carrying out experiments which very well simulate acetylcholine esterase inhibited by sarin. That reagent has often been used in the development of new antidotes. Until now the possibilities of reactivation of inhibited acetylcholine esterase with 40 antidotes, similar to pyridinealdoxime methiodid (PAM) (including newlysynthesized ones) have been researched. Among the antidotes tested in that experiment was the new hydrophobic compound of the 2PAM type - 2-[(hydroxyimino)methyl]-1-[4(tert-butyl)benzyl] pyridinium bromide (3), which was revealed to have highest reactive activity.

A research group have synthesized 12 analogues of organophosphorus nerve agents with 3-chloro-7-oxy-4-methylcoumarin group. Among them are analogues of pesticides paraoxon, parathion and dimefox and also the nerve agents diyzopropylflorphosphonate, tabun, sarin, cyclosarine, soman, VX and Russian VX. The results of acetylcholine esterase inhibition, in vivo toxicity tests of the representative analogue cyclosarin and kinetic tests with phosphotriesterase (PTE) taken from Pseudomonas diminuta and serum paraoxanase (PON1), taken from mammals confirm that the analogues effectively emulate the parent nerve agents. That makes them suitable tools for various scientific tests and experiments, for example tests on enzymes, which effectively metabolize nerve agents in living organisms and thus decrease the toxic effect of chemical warfare agents (4).

When rats are intravenously injected (iv) with a substance similar to soman and an organophosphorus chemical compound [bis (isopropylmethyl) phosphonate, BIMPand bis (pinacolyl methyl) phosphonate, BPMP] an increase of tyrosine phosphorylation of certain proteins of the cytosolic fraction of the brain is observed. Activation of c-Jun N-terminal kinase (JNK), as well as a slight activation of mitogen-activated protein kinase (MAPK) in the cytosolic fraction are also observed. The activation of these enzymes can be attributed to the high toxicity of these nerve agents (5).

Atropinised rats were intoxicated with a dose of soman, 6 or 8 times $\mathrm{LD}_{50}$ and after that treated with oxym HI-6, a few hours after intoxication. Oral or intravenous application of pinacolyl dimethylphosphinate (PDP), a soman simulator, introduced at gradually increasing intervals, before intoxication with soman, obviously turns out to be very active in HI-6induced recovery. Therapeutically, PDP is active only when introduced immediately after soman intoxication and treatment with oxym (6).

When laboratory rats are intoxicated with high doses of soman, (5-8 X LD $\mathrm{LD}_{50}$ ), that chemical compound is stored in temporary "depot", from where it is gradually released. In this way, no matter that the rats have been treated with reactivatorHIM-6 and atropine, the soman released from the depot re-intoxicates the organism so that death can occur in a few hours. Soman simulators, i.e. non-toxic structural analogues of soman have been synthesized. They are capable of preventing death in rats intoxicated with soman by modifying the process of storing and releasing soman from that depot. Earlier experiments showed that preventive treatment with the simulator pinacolyl dimethyl phosphinate (PDP), combined with HI-6 and atropine decreases the toxic effect of soman. Apart from that the rats were found to be of good overall condition as regards their health condition and neural functions. Quantitative experiments on the rats' behaviour were also carried out. A microprocessor system was used to measure the coordination behavior of rats. Residuous effects on the behavior of laboratory rats, after successful treatment were assessed. Animals treated with atropine sulphate $(25 \mathrm{mg} / \mathrm{kg}$, intraperitoneal application), soman $\left(5 \mathrm{X} \mathrm{LD}_{50}\right.$, intravenous application), HI-6 (56 mg/kg, intravenous application) and soman simulator PDP, were compared with animals treated with the same substances but without PDP (7).

Soman simulators have been synthesized. The pinacolyl group in their structure has been changed, the phospholine oxygen has been substituted with sulfur, or the phosphorus combined methyl groups have been substituted with ethyl or methoxy groups. All these chemical compounds have been synthesized 
with the aim of investigating their capacity of diminishing the harmful effects of soman intoxication by means of oxyms (8).

All three chemical warfare agents of soman, paraoxon and phosphocholine cauce holinergic symptoms, inducing progressive dose dependent necrosis of the skeletal muscle fibres of laboratory rats. The severity of myopathy depends on the critical decrease of the activity and the duration of acetylcholine esterase inhibition (AChE) (9).

Chemical nerve agents can cause seizures, status epilepticus, brain leisures. Paraoxon has been successfully used as a simulant of warfare agents in this respect, as well as in the search for new therapeutic strategies for diminishing the toxic effects of such nerve agents (10).

The thermochemical models CBS-QB3 и G4 have been used for collecting energy and structural data about a multitude of molecules with three and five valence phosphorus atoms, which can be used as simulants of chemical warfare agents. Comparison between the calculated and previously suggested vibration frequencies and the energy of connection dissociation was made (11).

The organophosphorus insecticide demeton-Smethyl (DSM) is considered a good substitute of the highly toxic nerve agent VX for the purpose of investigating its absorption through the skin due to their similar physical and chemical properties and their in vitro percute way of penetration (12).

An research team have tested 14 nerve agents, which emulate the toxic effects of tabun, sarin, soman and cyclosarin. They were revealed to be suitable substitutes for real nerve agents. They form co-valence adducts with human butirylcholine esterase, which is exactly what happens when real warfare agents are used (13).

\section{CONCLUSION}

In many cases regarding scientific research on the toxic effects of chemical warfare agents, simulants can be used. This does not affect the quality of the investigation but substantially reduces the risk of accidents and provide safe environment for the researchers involved.

\section{ACKNOWLEDGEMENTS}

This article has been supported by scientific projects №7/2016 of Medical faculty, Trakia University.

\section{REFERENCES}

IVANOV V., et al.

1. Popov I., Popov G, Popov Tsv., Popova D. Chemical weapons. Military publishing House, Sofia, 2016.

2. Charalampiev M. Chemical weapons. Faber, Veliko Turnovo, 2017.

3. Ohta H.,Ohmori T, Suzuki S, Ikegaya H, Sakurada K, Takatori T. New safe method for preparation of sarin-exposed human erythrocytes acetylcholinesterase using non-toxic and stable sarin analogue isopropyl p-nitrophenyl methylphosphonate and its application to evaluation of nerve agent antidotes. Pharm Res. 23(12):282733, 2006.

4. Briseño-Roa $L^{1}$, Hill J, Notman S, Sellers D, Smith AP, Timperley CM, Wetherell J, Williams NH, Williams GR, Fersht AR, Griffiths AD.. Analogues with fluorescent leaving groups for screening and selection of enzymes that efficiently hydrolyze organophosphorus nerve agents. $J$ Med Chem. 49(1):246-55, 2006

5. Niijima $H^{1}$, Nagao $M$, Nakajima $M$, Takatori T, Iwasa M, Maeno Y, Koyama H, Isobe I. The effects of sarin-like and soman-like organophosphorus agents on MAPK and JNK in rat brains. Forensic Sci Int. 112(2-3): 171-8, 2000

6. Van Helden HP, van der Wiel HJ, Wolthuis OL. Prophylactic and therapeutic efficacy of the soman-simulator, pinacolyl dimethylphosphinate. J Pharm Pharmacol. 38(6):439-45, 1986.

7. Wolthuis OL, Vanwersch RA, Van Helden HP. Residual behavioral incapacitation after therapy of soman intoxication: the effect of a soman simulator. Neurobehav Toxicol Teratol. 8(2):127-30, 1986.

8. van Helden HP, Benschop HP, Wolthuis OL. The prophylactic efficacy of various simulators against intoxication with the organophosphate soman: structure-activity studies. J Pharm Pharmacol.38(1):19-23, 1986.

9. Dettbarn WD. Pesticide induced muscle necrosis: mechanisms and prevention. Fundam Appl Toxicol. 4(2 Pt 2):S18-26, 1984.

10.Greget R ., Dadak S ., Barbier L., Lauga F ., Linossier-Pierre S ., Pernot F ., Legendre A ., Ambert N ., Bouteiller JM ., Dorandeu F., Bischoff S ., Baudry M ., Fagni L ., Moussaoui S . Modeling and simulation of organophosphate-induced neurotoxicity: Prediction and validation by experimental studies. Neurotoxicology. 54:140-152, 2016.

11.Hahn DK ., RaghuVeer KS, Ortiz JV. Simulant molecules with trivalent or 
pentavalent phosphorus atoms: bond dissociation energies and other thermodynamic and structural properties from quantum chemical models. $J$ Phys Chem A. 115(30):8532-9, 2011.

12.Bazire A, Gillon E, Lockridge O, Vallet V, Nachon F. The kinetic study of the inhibition of human cholinesterases by demeton-S-methyl shows that cholinesterase-based titration methods are
IVANOV V., et al. not suitable for this organophosphate. Toxicol In Vitro. 25(3):754-9. 2011.

13. Gilley $C^{1}$, MacDonald $M$, Nachon $F$, Schopfer LM, Zhang J, Cashman JR, Lockridge O. Nerve agent analogues that produce authentic soman, sarin, tabun, and cyclohexyl methylphosphonate-modified human butyrylcholinesterase. Chem Res Toxicol. 22(10):1680-8, 2009. 